\title{
A Study on Determining the Priorities of Expressway Construction Using AHP and LP
}

Eizo Kinoshita

Kobe City College of Technology

\begin{abstract}
Roads are the most universal and basic traffic facilities indispensable to daily life and industrial activities. They also form living environments and serve as disaster prevention spaces and public facility. Road improvement and maintenance in Japan, however, is far behind and speeding up of it is necessary from various viewpoints.

Planning and construction of expressways are specially urgent. It is desirable to evaluate the priorities of expressways in the network and construct them in order from one required most urgently to carry forward effective construction using limited resources effectively.

My study pertains to the procedure of deciding the construction priorities of expressways in the Analytic Hierarchy Process (AHP) and Linear Programming (LP).
\end{abstract}


1. Introduction

In the planning and construction of two or more expressways, a big problem is which one should be constructed first. The decision, however, is dependent on the standpoint, subjectivity, and value viewpoints of the decision maker. Today, value viewpoints are particularly diversified and they frequently cause differences of opinion. For instance, the profitability of an expressway may be low even though the expressway is desirable in view of local utility and traffic density, while a highly profitable expressway may create traffic nuisances along the route.

The construction priorities of expressways are easily determined if only one viewpoint (for instance, the option of the road constructor. or the residents along the expressway) is concerned but not if two or more are concerned.

This paper discusses several methods of determining the construction priorities for two or more express,ways according to the evaluation indexes of the expressways as assessed from several viewpoints. The methods employed in this study are the Analytic Hierarchy Process (AHP) and Linear Programming (LP).

2. Alternatives and Evaluation Factors

Expressways being prioritized are called alternatives, while items used to determine this are called evaluation fctors. In my study, the alternatives nine imaginary expressways, and the evaluation factors include the following five criteria. (I) Supplementary and access functions to national highways or arterial highways (II) Local utility function (III) Goods transportation flow function (IV) Investment efficiency (V) Usefulness. (I) is an evaluation index from a viewpoint of the network function and is expressed by traffic flow to and from a connected national 


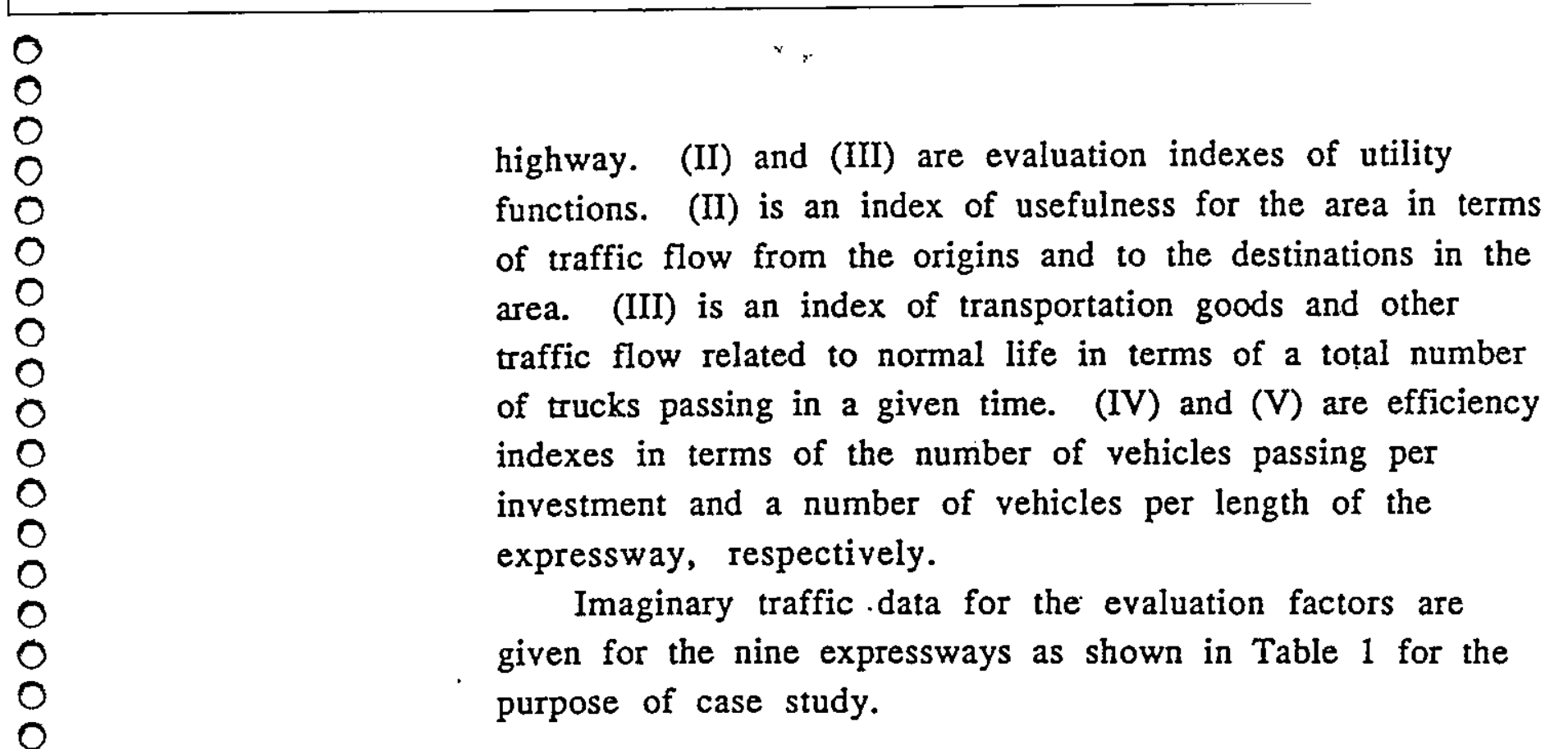

Table 1 Evaluation Data of Imaginary Expressways

\begin{tabular}{|c|c|c|c|}
\hline $\begin{array}{c}100 \\
\text { vehicles }\end{array}$ & $\begin{array}{l}100 \\
\text { vehicles }\end{array}$ & $\begin{array}{c}100 \\
\text { vehicle's }\end{array}$ & $\begin{array}{l}\text { Vehicles/ } \\
\text { Hundred } \\
\text { million yen }\end{array}$ \\
\hline
\end{tabular}

\begin{tabular}{|c|rrrrl|}
\hline Route No. & (I) & (II) & (II) & (IV) & (V) \\
\hline 1 & 130 & 330 & 40 & 40 & 60 \\
2 & 80 & 180 & 30 & 45 & 55 \\
3 & 90 & 140 & 20 & 60 & 45 \\
4 & 40 & 120 & 20 & 55 & 30 \\
5 & 250 & 200 & 280 & 70 & 65 \\
6 & 60 & 80 & 50 & 65 & 40 \\
7 & 50 & 40 & 40 & 30 & 38 \\
8 & 75 & 90 & 70 & 55 & 35 \\
9 & 20 & 80 & 40 & 50 & 48 \\
\hline
\end{tabular}

Furthermore, pair comparisons of importance among evaluation factors were made for cases $A$ and $B$, and the results are given in Tables 2 and 3 . For instance, the circles in rows 1 and 2 of Table 2 mean that evaluation factor (I) is deemed more important than the factor (II). Importance in case $\mathrm{A}$ is quite converse to that of case $\mathrm{B}$. 
3. Description of the Analytic Hierarchy Process (AHP)

Saaty proposed the AHP method in 1971, a decision making method using various evaluation criteria under uncertain conditions. The method is one of problem solving and decision making adequately combining subjective. judgements and system approaches.

The AHP process is comprised the following three steps.

Table 2 Case $\mathrm{A}$

\begin{tabular}{|c|c|c|c|c|c|}
\hline $\begin{array}{c}\text { Evaluztion } \\
\text { factor }\end{array}$ & (I) & (II) & (III) & (IV) & (V) \\
\hline (I) & & $\bigcirc$ & $\bigcirc$ & $X$ & $\triangle$ \\
\hline (II) & & & & $\triangle$ & $\times$ \\
\hline (III) & & & & $\triangle$ & $X$ \\
\hline (IV) & & & & & $\times$ \\
\hline (V) & & & & & \\
\hline
\end{tabular}

Table 3 Case B

\begin{tabular}{|c|c|c|c|c|c|}
\hline $\begin{array}{c}\text { Evaluation } \\
\text { factor }\end{array}$ & (I) & (II) & (II) & (IV) & (V) \\
\hline (I) & & $X$ & $\times$ & $O$ & 0 \\
\hline (II) & & & $X$ & $\Delta$ & 0 \\
\hline (III) & & & & $\Delta$ & 0 \\
\hline (IV) & & & & & 0 \\
\hline (V) & & & & & \\
\hline
\end{tabular}

(1) Step One

A problem with complicated situations is broken down into a hierarchical structure. The top level is the overall objective. The elements of the lower levels are determined 
by the subjective judgement of the decision maker in relation to the elements of the immediately higher level. An

allowable number of elements for each line is up to $7 \pm 2$. The number of levels is determined by the structure of the problem and is not limited. The lowest level consists of alternatives.

\section{(2) Step Two}

The elements of each level are weighed against each other. Pair comparisons among the elements of a line are determined according to the evaluation criteria and the elements of the immediately higher level. If $n$ is used as a comparative element number, the decision maker compares $\mathrm{n}(\mathrm{n}-1) / 2$ judgements.

Intensity numbers used for comparisons are $1 / 9,1 / 8, \ldots$ $\ldots \ldots 1 / 2,1,2, \ldots 8$, and 9 . Each number is defined in Table 4.

Pair comparison matrices are acquired by the above comparison. The weight (unknown) of each element in each line is calculated from the matrices based on the eigenvalue concept of linear algebra (refer to Bibliography 2).

Pair comparison matrices are reciprocal. However, it is $^{2}$ not possible to expect consistent pair comparisons through judgements from beginning to end. The uncertainty is evaluated by a consistency index (refer to Bibliography 2).

Table 4 Scale of Importance and Definitions

\begin{tabular}{|c|l|}
\hline Scale of Importance & \multicolumn{1}{|c|}{ Definition } \\
\hline 1 & equal importance \\
3 & slight importance \\
5 & strong importance \\
7 & very strong importance \\
9 & absolute importance \\
\hline
\end{tabular}




\section{(3) Step Three}

The weights among the elements of each level calculated as in the above para. (2) are used to determine the weight of the entire hierarchy. The priorities of the alternatives are thereby determined as for the overall objective. Finally, the consistency index of each pair comparison matrix is. multiplied by the priority of the corresponding evaluation element, and the products are added on the entire hierarchy.

Refer to Bibliogrphy 2 for mathematical background of the AHP method.

4. Analysis by the AHP Method

Decisions of road improvement priorities are analyzed in the Bibliography 3. Similar analyses are carried out in this section.

\section{(1) Step One}

The analytic hierarchy for determining expressway construction priorities is shown in Fig. 1.

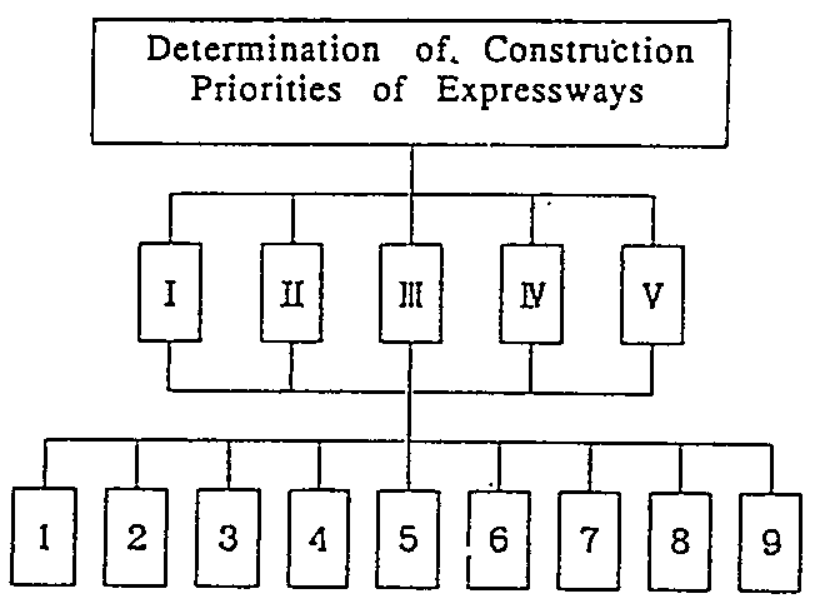

Fig. 1 Hierarchy for Determining Construction Priorities of Expressways . 
through $V$ ) are omitted but the attractiveness (usefulness) of each route was calculated from the matrices.

(3) Step Three

Each of the nine expressways were evaluated overall on the principle of the analytic hierarchy according to the acquired results as outlined so far. The results are given in Table 7 for cases $\mathrm{A}$ and $\mathrm{B}$.

\section{Table 7}

Case A

\begin{tabular}{|c|l|}
\hline $\begin{array}{c}\text { Expressway } \\
\text { No. }\end{array}$ & $\begin{array}{c}\text { Overall } \\
\text { Evaluation }\end{array}$ \\
\hline 5 & 0.211 \\
1 & 0.135 \\
2 & 0.115 \\
3 & 0.111 \\
6 & 0.097 \\
8 & 0.095 \\
9 & 0.085 \\
4 & 0.079 \\
7 & 0.072 \\
\hline
\end{tabular}

Case B

\begin{tabular}{|c|c|}
\hline $\begin{array}{c}\text { Expressway } \\
\text { No. }\end{array}$ & $\begin{array}{c}\text { Overall } \\
\text { Evaluation }\end{array}$ \\
\hline 5 & 0.313 \\
1 & 0.118 \\
8 & 0.103 \\
2 & 0.094 \\
6 & 0.089 \\
3 & 0.085 \\
9 & 0.070 \\
4 & 0.068 \\
7 & 0.060 \\
\hline
\end{tabular}

In the pair comparisons of the criteria, calculations were conducted deeming a circle $\bigcirc$ as slight importance (3) or a very strong importance (7) (Refer to Table 4). The results nearly agreed with those given in Table 7 .

5. Analysis by the Linear Programming (LP) Method

Selection of an expressway $X_{i}$ with known constituents (importance $A_{j}$ among criteria and evaluation $Y_{i j}$ of expressway $X_{i}$ against criteria) may be deemed as a problem 
of optimization with two or more evaluation factors $(\mathrm{Al} \sim \mathrm{An})$. An optimum selection for every criterion is desirable, but generally not actually possible, requiring the taking of an alternative deemed the most desirable according to overall evaluation.

The problem, however, may be solved by checking each of the alternatives $X_{1}$ to $X_{m}$ to see if they can be optimized under condition (1).

$$
\mathrm{Ak}>\mathrm{A} \text { or } \mathrm{Ak}<\mathrm{A} \text { or } \mathrm{Ak}=\mathrm{A}
$$

If an optimum alternative $\mathrm{Xk}$ is determined under condition (1), it may be concluded, by repeating the above process, that only $X_{k}$ can be optimized.

Based on the above concept, evaluation factors $A 1$ to $A_{n}$ were set to evaluation function $f(A 1, A 2, \ldots . A n)$ and analysis using the linear programming method was tried.

If evaluation criterion $A j$ is considered, each factor may have evaluation criteria. Assuming a minimum level aj and an ideal level- $\bar{a} j$, the suitability of the criterion is determined from the levels and an evaluation value $Y_{i j}$. If the suitability is $\mathrm{Sij}$, equation (2) would result as follows:

$$
\begin{array}{lll}
\text { If } & \cdot Y_{i j} \leqq a j, & S_{i j}=0 \\
\text { If } & \underline{a j}<Y_{i j}<\overline{a j}, \quad S_{i j}=\frac{\left(Y_{i j}-\underline{a j}\right)}{(\bar{a} j-\underline{a j})} \\
\text { If } & \overline{a j} \leqq Y i j, & S_{i j}=1.0
\end{array}
$$

Operator $\alpha \mathrm{j}$ is employed to measure the relative degree of suitability among the evaluation factors. The evaluation value $f$ ( $E i$ i of each alternative $\left(X_{i}\right)$ is acquired using equation (3).

$$
f(E i)=\sum_{j=1}^{n} \alpha j S i j
$$


However, limiting conditions are given by equation (4).

$$
\begin{aligned}
& \alpha \mathrm{k}>\alpha \ell \text { or } \alpha \mathrm{k}<\alpha \ell \text { or } \alpha \mathrm{k}=\alpha \ell \\
& (\mathrm{k}=1,2, \ldots . ., \mathrm{n} ; \ell=1,2, \ldots . ., \mathrm{n} ; \mathrm{k} \neq \ell) \\
& 0 \leq \alpha \mathrm{j} \leq 1.0
\end{aligned}
$$

Therefore, the construction priority is determined by solving $\mathrm{m}(\mathrm{i}=1, \ldots . \mathrm{m})$ pieces of the linear programming problem to maximize equation (3) under the restrictions expressed by the equation (4).

The results of analysis by the LP method are compared with those of the AHP method as in Fig. 8. The expressway identification numbers are arranged in order of higher priority from top to bottom.

Table 8

Case A
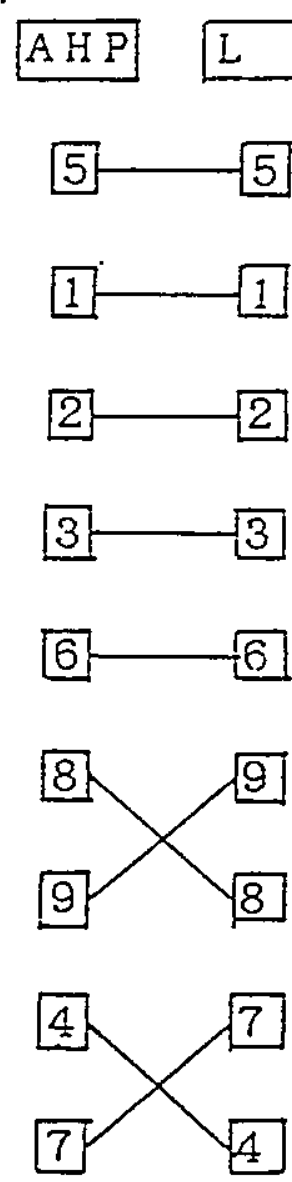

Case B
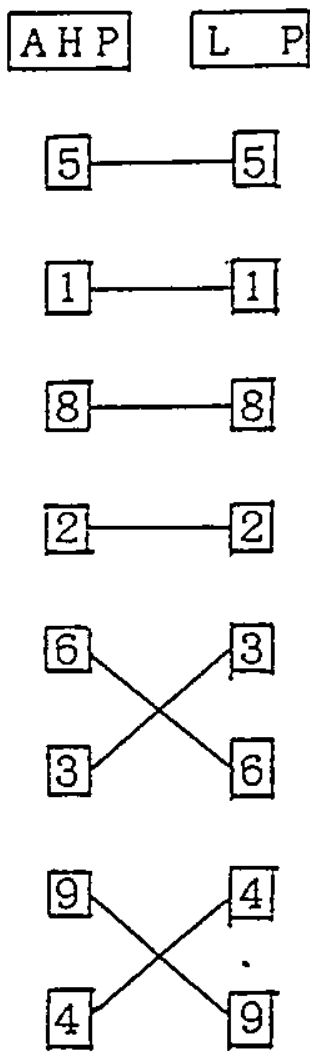

7 


\section{Conclusions}

The processes of determining the construction priorities of expressways by the AHP method and the LP method have been analyzed, showing the following features of the analysis, and other findings.

(1) Analysis was conducted by two methods, AHP and LP, on a problem including two scenarios (cases $A$ and $B$ ) and two or more evaluation factors (I to $\mathrm{V}$ ) with little difference in the results between the two methods.

(2) The AHP method is easier to calculate, carries out pair comparisons of evaluation factors in nine steps, and weighs each factor. The method can deal with intangible evaluation factors and carry out sensitivity analysis and cost-benefit analysis easily. However, it was observed that calculation is difficult if the number of expressways exceeds ten.

(3) The LP method is stricter in calculation and deals with many expressways. The method, however, conducts Pair... comparisons among evaluation factors only up to three steps $(O, \triangle, X)$, can not deal with intangible evaluation factors, and the $\cdot$ calculations are complicated.

- The AHP method was compared with the LP method but needs to be further compared with various multi-objective decision making methods (multi-objective linear programming, goal programming, etc.). It is also necessary to analyze evaluation methods, etc. combined with the AHP method.

I wish to thank Toshiaki Okamoto, Toshi Kotsu Keikaku Kenkyusho, for providing valuable data and many helpful suggestions in this study. 
Bibliography:

1) Thomas L. Saaty: "The Analytic Hierarchy Process", McGrawHill, 1980

2) Eizo Kinoshita: "An Introduction to Multivariate Statistical Analysis", Keigaku Shuppan, 1987

3) Eizo Kinoshita: "A Study on Determining Priority of

Improvement for Road Using AHP" Traffic Engineering,

Vol. 25, No.2, PP9 16, March 1990 